\title{
Particle dynamics in the central \\ Pacific Ocean: Insights from Th and Pa isotopes
}

\author{
MARTY FLEISHER $^{1}$, ROBERT ANDERSON ${ }^{2}$, ERIN \\ BLACK $^{1}$, NICHOLAS CARRACINO ${ }^{3}$, R. LAWRENCE \\ EDWARDS ${ }^{4}$, CHRISTOPHER T HAYES ${ }^{5}$, PHOEBE J. \\ LAM $^{6}$, XIANGLEI LI ${ }^{4}$, NEIL A REDMOND ${ }^{5}$, SOPHIE \\ ROJAS $^{3}$ AND PETER SCHROEDL ${ }^{4}$
}

${ }^{1}$ Lamont-Doherty Earth Observatory

${ }^{2}$ Columbia University

${ }^{3}$ University of California Santa Cruz

${ }^{4}$ University of Minnesota

${ }^{5}$ University of Southern Mississippi

${ }^{6}$ University of California, Santa Cruz

Presenting Author: christopher.t.hayes@usm.edu

Thorium-232 (t 1 1 $2 \sim 14 \mathrm{Ga}$ ), Thorium-230 (t 1/2 75.7 ka), and Protactinium-231 (t $1 / 2 \sim 32.8 \mathrm{ka})$, are naturally-occurring, powerful tools for evaluating large scale particle dynamics, sources of trace elements and isotopes (TEIs) to the ocean, and the internal fluxes of key chemical constituents, such as organic carbon and iron. Dissolved and size-fractionated particulate samples were collected in the fall of 2018 along the GP15 152 ${ }^{\circ} \mathrm{W}$ GEOTRACES transect (Alaska to Tahiti). Filtered seawater samples, as well as subsamples of particulate matter filters were analyzed for $\mathrm{Th}$ isotopes and ${ }^{231} \mathrm{~Pa}$ in our labs. Preliminary results indicate that the distributions of these elements are influenced by both atmospheric sources (e.g., dust arriving to the North Pacific from Asian sources) and boundary processes (i.e., inputs from the Alaskan margin). We will discuss the relative importance of these factors to the different biogeochemical regimes crossed on our N-S transect and how different processes may impact the fluxes of TEIs and organic carbon. Interestingly, the dissolved ${ }^{231} \mathrm{~Pa} /{ }^{230} \mathrm{Th}$ ratios near the Alaskan Margin are atypically low compared to those found on previous GEOTRACES campaigns (e.g., at the Peruvian margin) and increase away from the margin. We will examine this divergence from 'classical' boundary scavenging and its implications for TEI cycling in the North Pacific. 